\title{
A European perspective on an American discussion
}

To the Editor - The term 'clinical trial' is an intrusive beast, bringing with it criteria, requirements and needed justifications that we all believe some research should be subjected to but many believe 'Not my research!'

The National Institutes of Health (NIH) has crossed sacred lines: the line between 'fundamental research' and 'clinical research' and the line between the biomedical sciences and the behavioural sciences. And it did so by striking at the heart of where that line runs: scientific methodology. The NIH has sought to define 'clinical research' according to its design: "one or more human subjects are prospectively assigned to one or more interventions"1. This seemingly ignores a fundamental distinction between houses of research: some being called 'clinical', some being called 'fundamental' and some being called 'behavioural'.

The NIH's revised definition has raised 'serious concerns' and led to 'fierce pushback' in some fundamental and behavioural sciences ${ }^{2}$. A petition has been signed by 3,580 scientists, nearly all working in academia ${ }^{3}$. Although Europe has not extended the term 'clinical trial' to behavioural research (perhaps largely because of distinctions in member state research structures, funding, and thus legislation and regulation), Europe knows all too well how hard academia will resist such an invasion.

When Europe introduced the Clinical Trials Directive ${ }^{4}$ in April 2001, it originally went largely unnoticed in the academic community. On 9 December 2003, a petition was hurriedly cobbled together and signed by a broad spectrum of academic researchers all fearing the approaching 1 May 2004 implementation date. By 15 January 2004, more than 2,000 researchers (including some US researchers) had signed a document that promised a doomsday scenario for academic research if the legislation was not 'repealed's.

The European authorities' failure to understand the differences between the houses of research and to respect boundaries promised nothing less than the death of research. The petition began by asking, "Why did the European Union decide to stop cancer research?" Academic research, it warned, would become too bureaucratic, too burdensome, too expensive, too time consuming. Sound familiar?

The NIH's decision and the US scientists' reaction to it is an American discussion. From across the pond, we appreciate that. We also appreciate the NIH's desire to see stewardship prevail in all research with human subjects ('clinical trials' and otherwise) aiming to "elevate the entire biomedical research enterprise to a new level of transparency and accountability" ${ }^{\text {. }}$

This goal would appear to outstrip concerns regarding 'a raft of new requirements' or hesitancy to report results on ClinicalTrials.gov ${ }^{2}$. In Europe, we know the shock, the outrage, the angst. The www. SaveEuropeanResearch.org website is now defunct, the petition forgotten. We also know that this invasive animal, the clinical trial, is good for science and ethics. More than 15 years after the introduction of the European legislation, academic research in Europe has gone to new levels: clinical trial networks have joined academics at the hip; clinical trial units have sprung up across the academic landscape; and academia is a leading voice in stewardship and best practices for clinical trials.

The beast did not kill academic research. The new regulation of 'clinical trials' enhanced, expanded and benefited the research of those who initially resisted.

Francis P. Crawley

Good Clinical Practice Alliance - Europe (GCPA),

Brussels, Belgium.

e-mail: fpc@gcpalliance.org

Published online: 22 January 2018

https://doi.org/10.1038/s41562-018-0293-8

\section{References}

1. NIH's definition of a clinical trial (NIH, 2017); https://grants.nih. gov/policy/clinical-trials/definition.htm.

2. Kaiser, J. Some scientists hate NIH's new definition of a clinical trial. Here's why. Science News https://doi.org/10.1126/science. aan7122 (19 July 2017).

3. Wolfe, J. et al. Open Letter to NIH Director Francis Collins (iPetitions, 2017); https://www.ipetitions.com/petition/openletter-nih-collins.

4. Directive 2001/20/EC of the European Parliament and of the Council of 4 April 2001 on the approximation of the laws, regulations and administrative provisions of the Member States relating to the implementation of good clinical practice in the conduct of clinical trials on medicinal products for human use, O.J. L 121 (2001); https://ec.europa.eu/health/sites/health/files/ files/eudralex/vol-1/dir_2001_20/dir_2001_20_en.pdf.

5. Moulton, B. Br. Med. J. 328, 286 (2004).

\section{Competing interests}

F.P.C. is the Executive Director of the Good Clinical Practice Alliance - Europe (GCPA). The GCPA is an independent, not-for-profit organization working to enhance the science and ethics of health-related research in Europe and globally. F.P.C. has held professional and paid positions in academic, not-for-profit and intergovernmental organizations. He has never been employed in the biomedical industry. F.P.C. has acted as a speaker and advisor to NIH institutions on specific aspects of ethics, science and policy. He has not been involved in the planning of the NIH clinical trials policy or its implementation. 